\title{
Pattern of aortic aneurysms in an African country
}

\author{
Julius A. Ogeng'o, BSc, MBChB, PhD, Beda O. Olabu, BSc Hons, and Justus P. Kilonzi, BSc Hons
}

Objective: We sought to describe the regional, age, and sex distribution; diagnosis; treatment; and outcome of aortic aneurysms in a Kenyan population.

\begin{abstract}
Methods: This was a retrospective study at Kenyatta National Hospital, Kenya. Records of black African patients whose final diagnosis was aortic aneurysm over the period from January 1998 to December 2007 were examined. Frequencies and means are presented in tables and bar charts.
\end{abstract}

Results: Two hundred sixty-four (92 male and 172 female patients) files were analyzed. The mean age was 56.15 years. Two hundred twenty-three $(84.5 \%)$ aneurysms occurred in the abdominal aorta, followed by the descending aorta $(7.5 \%)$, ascending aorta, $(3.8 \%)$ and arch $(1.9 \%)$. In $2.3 \%$ of cases, both the abdominal and thoracic aortas were affected. The male/female ratio was 1:1.9. Pain with swelling or a pulsatile mass was the predominant feature. More than $50 \%$ of the cases were diagnosed by means of ultrasonographic analysis. Sixty-one $(23.1 \%)$ aneurysms were ruptured, and of this group, $44(72.1 \%)$ patients died. Successful open surgical repair was done in $157(59.5 \%)$ patients. Hypertension was a comorbidity in 137 (51.9\%) cases.

Conclusions: Aortic aneurysms in Kenya show abdominal segment and female predominance, occur 10 to 15 years earlier than in white populations, and carry high mortality from rupture. Hypertension was the leading associated risk factor. Ultrasonographic screening and control of blood pressure might be useful preventive measures. (J Thorac Cardiovasc Surg 2010;140:797-800)

The pattern of aortic aneurysms varies between countries depending on ethnic ${ }^{1}$ and geographic ${ }^{2}$ differences related to the burden of risk factors. ${ }^{3}$ Isolated reports, mainly from Southern Africa, suggest that among black Africans, aneurysms are uncommon, occur in younger persons without sex bias, and are nonatherosclerotic. ${ }^{1,4}$ Data on regional distribution are often conflicting, with some studies reporting no involvement of the thoracic aorta ${ }^{4}$ and others showing that the thoracic segment is affected more than abdominal segment. ${ }^{1}$ These differences could be related to etiopathogenic factors, such as infectious conditions, ${ }^{1}$ including HIV. 5

Some Sub-Saharan African countries, including Kenya, are undergoing an epidemiologic transition in which noncommunicable diseases initially thought to be rare are gaining prominence, and there are indications that among other conditions, atherosclerotic cardiovascular diseases are increasing because of higher longevity and lifestyle changes. ${ }^{6}$ As atherosclerosis becomes more important among Africans, its sequelae, including aneurysms, are expected to become increasingly evident. ${ }^{4}$ Because the aorta is the most frequent site of aneurysms, knowledge of the pattern of its involvement is important in the detection, treatment, and

\footnotetext{
From the Department of Human Anatomy, University of Nairobi, Nairobi, Kenya. Disclosures: None.

Received for publication June 24, 2009; revisions received Oct 27, 2009; accepted for publication Nov 8, 2009; available ahead of print Feb 22, 2010

Address for reprints: Beda O. Olabu, BSc Hons, Department of Human Anatomy,

University of Nairobi, PO, Nairobi, Kenya (E-mail: bedaotn@yahoo.com). $0022-5223 / \$ 36.00$

Copyright (C) 2010 by The American Association for Thoracic Surgery doi:10.1016/j.jtcvs.2009.11.023
}

prevention of this disease. Data from Africa, however, are scanty and altogether missing from Kenya. This study reports the site, age, and sex distribution; associated risk factors; diagnosis; and outcome of aortic aneurysms from this SubSaharan country.

\section{MATERIALS AND METHODS}

Records of black African patients with a diagnosis of aortic aneurysms from January 1998 to December 2007 at Kenyatta National Hospital were examined for site, age, and sex distribution; associated risk factors; diagnosis; and outcome. Kenyatta National Hospital is an 1800-bed capacity, level 6 , public referral facility with 41 cardiovascular surgery beds and 10 cardiovascular surgeons. It receives 80,000 inpatients per year from the entire East and Central African regions. Ethical approval for the study was obtained from the Kenyatta National Hospital Ethics and Research Committee. Only files with complete records and a confirmed diagnosis of aortic aneurysm were included. Those with incomplete records and those of nonblack Africans were excluded. Data obtained were analyzed with SPSS version 11.5 software (SPSS, Inc, Chicago, Ill). The results were presented by using tables and bar charts.

\section{RESULTS}

Two hundred eighty-two files were retrieved. Eighteen were excluded, 10 in whom the age was recorded only as "adult" and 8 who defaulted before diagnosis was confirmed. Two hundred sixty-four (92 male and 172 female patients) files were included in the study.

\section{Age Distribution}

Mean age was 56.15 years (range, $11-90$ years; $n=264$ ). The most affected age group was the 51- to 70-year age group $(50 \%)$. In the group younger than 50 years, $32.2 \%$ of the aortic aneurysms occurred, with $21.6 \%$ occurring 


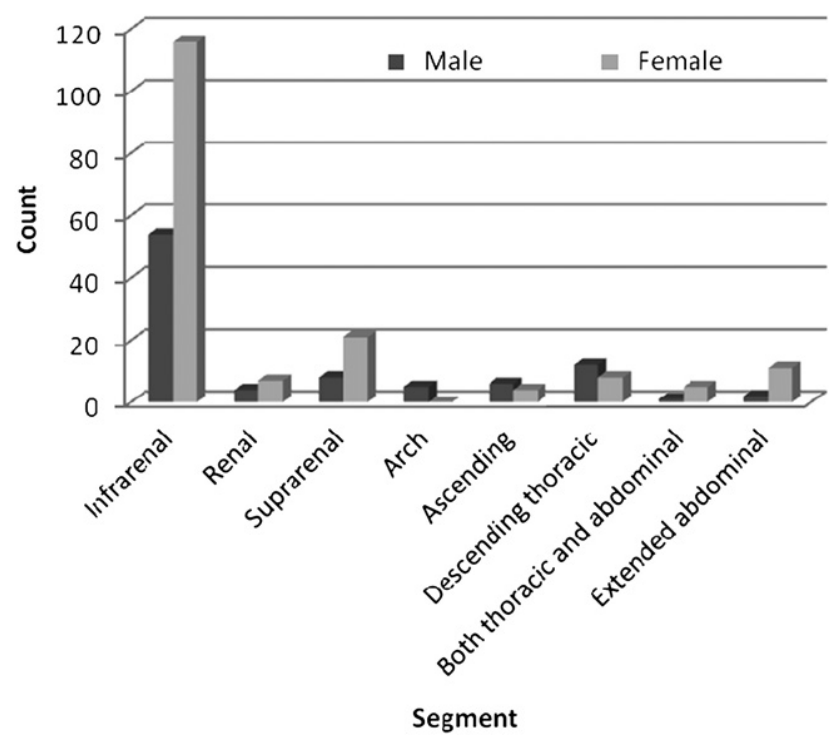

FIGURE 1. Sex distribution of aortic aneurysms.

before 40 years of age. Age affected varied with region involved. For example, aneurysms of the infrarenal segment predominantly occurred after 50 years of age, those of the renal and juxtarenal segments were observed only after 50 years of age, and those of the descending aorta occurred mainly between 21 and 30 years of age.

\section{Regional Distribution}

The abdominal aorta was involved in $223(84.5 \%)$ of the cases, and the thoracic aorta was involved in $35(13.3 \%)$. Both regions were simultaneously involved in $6(2.3 \%)$ of the cases. One hundred seventy $(64.4 \%)$ of all aortic aneurysms were in the infrarenal segment. The suprarenal segment was next, with $29(11.0 \%)$ cases, and the renal and juxtarenal segments were affected in only $11(4.2 \%)$ cases. In $13(4.9 \%)$ cases the aneurysms spanned more than 1 segment. In the thoracic aorta the descending part was involved in $20(7.6 \%)$ cases, the ascending part in $10(3.8 \%)$ cases, and the aortic arch in only $5(1.9 \%)$ cases. Six $(2.3 \%)$ aneurysms extended over both the thoracic and abdominal parts.

\section{Sex Distribution}

The overall female/male ratio was 1.9:1. This sex difference, however, was site (Figure 1) and age (Figure 2) dependent. There was notably a male predominance in the descending thoracic aorta and aortic arch. The male/female ratio was $1.4: 1$ before 40 years of age, nearly $1: 1$ before 50 years of age, and 1:2.5 after 50 years of age.

\section{Presentation and Diagnosis}

The most common mode of presentation was pain and swelling $(34.8 \%)$, followed by pulsatile mass $(17.8 \%)$ and pain alone $(17.0 \%)$ for abdominal aneurysms. In the thoracic

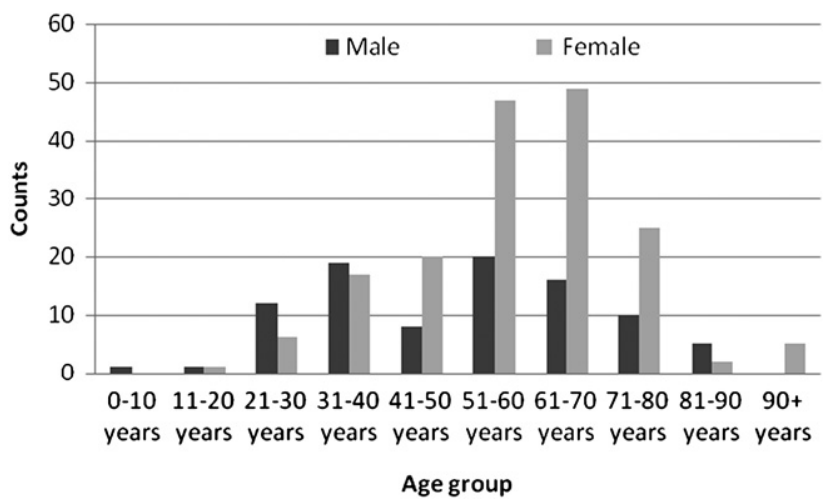

FIGURE 2. Incidence of aortic aneurysm by age and sex.

aneurysms the predominant feature was chest pain with or without palpitations. Diagnoses were made by means of ultrasonographic analysis (54.9\%), computed tomographic scanning $(21.6 \%)$, angiographic analysis $(9.5 \%)$, Doppler ultrasonographic analysis $(5.7 \%)$, echocardiographic analysis $(3.4 \%)$, plain radiographic analysis $(2.3 \%)$, and magnetic resonance imaging $(1.9 \%)$ and at surgical intervention $(0.8 \%)$.

\section{Risk Factors/Comorbidity}

Notable associated risk factors included hypertension $(51.5 \%)$, smoking $(11.4 \%)$, alcohol $(6.4 \%)$, obesity $(6.1 \%)$, infection $(4.6 \%)$, Marfan's syndrome (3\%), trauma $(1.1 \%)$, and multiple factors $(15.9 \%)$.

\section{Outcome}

Sixty-one $(23.1 \%)$ aneurysms ruptured either by the time of presentation or within the hospital while awaiting surgical intervention. Forty-four $(72.1 \%)$ of these died. One hundred seventy-seven $(67.0 \%)$ underwent successful open repair, and $43(16.3 \%)$ defaulted.

\section{DISCUSSION}

It is generally believed that aortic aneurysms are uncommon among black Africans. ${ }^{1,4}$ The present study, which was performed exclusively on black Africans, however, reveals that

TABLE 1. Mean ages of aortic aneurysm

\begin{tabular}{|c|c|c|c|}
\hline Author & \multicolumn{2}{|c|}{ Population } & $\begin{array}{c}\text { Mean } \\
\text { age }(\mathbf{y})\end{array}$ \\
\hline \multirow{3}{*}{$\begin{array}{l}\text { Present study } \\
\text { Costa and Robbs, } 1986^{4}\end{array}$} & \multicolumn{2}{|l|}{ Kenyan } & 56.15 \\
\hline & South African & White & 67.2 \\
\hline & & Black & 49.4 \\
\hline \multirow[t]{2}{*}{ Kitchen, $1989^{1}$} & \multirow[t]{2}{*}{ South African } & White & 66.3 \\
\hline & & Black & 51.2 \\
\hline Ishikawa and coworkers, $2004^{11}$ & Japanese & & 74 \\
\hline Pleumeekers and coworkers, $1995^{10}$ & White & & 75 \\
\hline Young and Osterlag, $1987^{7}$ & German & & 72.8 \\
\hline
\end{tabular}


in one hospital over a period of 10 years, there were more than 2 aortic aneurysms of about 6500 admissions every month, suggesting that they are more common than hitherto perceived. Because most aneurysms are caused by atherosclerosis, ${ }^{7}$ the substantial numbers imply that this disease is a significant cause of morbidity in Kenya. Hypertension, smoking, alcohol consumption, and obesity were associated risk factors in the current study, as in other populations, ${ }^{8}$ with only a small number associated with infection. This appears to support the epidemiologic transition in Africa.

\section{Outcome}

Rates of abdominal aortic aneurysm rupture vary between countries. ${ }^{8,9}$ In the current study $23.1 \%$ ruptured, with a mortality of $72.1 \%$, which is comparable with that in Hong Kong. ${ }^{8}$ The substantial proportion of rupture, including while awaiting surgical intervention, calls for greater vigilance in diagnosis and speed in repair of the aneurysm.

\section{Age Distribution}

The present study reveals a mean age of 56.15 years, with more than $20 \%$ of the cases occurring before the age of 40 years. This is comparable with results obtained in other African studies. ${ }^{1,4}$ It is, however, significantly lower than that reported for other populations (Table 1). ${ }^{1,4,7,8,10,11}$ It appears that aneurysms among black Africans occur at least 15 years earlier than in their white counterparts, even when living in the same environment. These differences might be related to the cause of aneurysms. ${ }^{1,4,5}$ However, it is probable that actual ethnic differences occur in age of onset of aneurysms.

\section{Regional Distribution}

Atherosclerotic aneurysms have been reported to occur more commonly in the infrarenal segment of the aorta, whereas inflammatory and dissecting aneurysms are more common in the thoracic aorta. ${ }^{12}$ The findings of this study, in which $84.5 \%$ of aortic aneurysms occur in the abdominal region, differ with those from another African state, in which more than $50 \%$ of aortic aneurysms were thoracic, ${ }^{1}$ but corroborate those of studies on predominantly white populations. The increased propensity of the abdominal aorta to result in an aneurysm parallels its vulnerability to atherosclerosis. ${ }^{13}$ Thus the observation that the distribution of aneurysms in Kenyans resembles that in white populations implies that atherosclerosis is already an established problem in this African state.

Another notable difference between the findings of the present study and others on black Africans ${ }^{1,4}$ is that all parts of the thoracic aorta are affected. In white populations the ascending aorta is the next most affected part after the abdominal aorta. ${ }^{13}$ In the present study the descending aorta was more involved than the ascending aorta. These apparent ethnic variations might be due to different pathomechanisms of aneurysms involved in the aorta. The widespread involve- ment of the thoracic aorta observed in the present study could be related to etiopathogenic factors operational in black African populations, such as nonspecific aortoarteritis, tuberculous arteritis, ${ }^{4}$ syphilis ${ }^{1}$ bacterial infections, vasculitides, connective tissue disorders, ${ }^{9}$ and HIV. ${ }^{5}$ Indeed, in the current study infections, Marfan's syndrome, and trauma collectively constituted a significant proportion of implicated causative factors.

\section{Sex Distribution}

Aortic aneurysms are believed to occur more commonly in male than in the female subjects. ${ }^{3}$ The observation of the current study that the overall male/female ratio is nearly 1:2 appears at variance with these reports. There is, however, male predominance before the age of 40 years, and female predominance becomes most marked after the age of 50 years. This supports the view that reproductive events, including circulating estrogens in premenopausal female subjects, might be protective against aneurysm formation. The heterogeneity in sex predominance demonstrated in the thoracic aorta suggests that other factors, such as ethnic, ${ }^{1}$ geographic, ${ }^{2}$ and comorbid ${ }^{8}$ conditions, might be relevant considerations.

\section{CONCLUSION}

Aortic aneurysms in the Kenyan population show abdominal segment and female predominance, occur 10 to 15 years earlier than in the white population, and carry high mortality from rupture. The majority are associated with hypertension and can be diagnosed by means of ultrasonographic analysis. Control of blood pressure and ultrasonographic screening for abdominal pain and masses are recommended.

We thank the registry officers at Kenyatta National Hospital for clerical assistance and Ms Wambui Chinga for secretarial assistance.

\section{References}

1. Kitchen ND. Racial distribution of aneurysms in Zimbabwe. J R Soc Med. 1989; 82:136-8.

2. Coggon D, Martyn C, Osmond C. Mortality from aortic aneurysm in migrants between countries of England and Wales: evidence for causes acting early in life. QJM. 1997;90:133-7.

3. Ogata T, Mackean GL, Cole CW, Arthur C, Andreou P, Tromp G, et al. The lifetime prevalence of aortic aneurysms among siblings of aneurysm patients is eightfold higher than among siblings of spouses. An analysis of 187 aneurysm families in Nova Scotia, Canada. J Vasc Surg. 2005;42:891-7.

4. Costa M, Robbs JV. Abdominal aneurysms in a black population: clinicopathological study. Br J Surg. 1986;73:554-8.

5. Nair R, Robbs JV, Naidoo NG, Woolgar J. Clinical profile of HIV-related aneurysms. Eur J Endovasc Surg. 2001;21:285-6.

6. Mensah GA. Ischaemic heart disease in Africa. Heart. 2008;94:836-43.

7. Young R, Osterlag H. Incidence, aetiology and risk of rupture of aortic aneurysm. An autopsy study. Dtsch Med Wochenschr. 1987;112:1253-6.

8. Cheng SWK, Ting ACW, Tsang SHY. Epidemiology and outcome of aortic aneurysm in Hong Kong. World J Surg. 2003;27:241-5.

9. Lederle FA, Johnson GR, Wilson SE, Ballard DJ, Jordan WD, Blebea J, et al. Rupture rate of large abdominal aortic aneurysms in patients refusing or unfit for elective repair. JAMA. 2002;287:2968-72. 
10. Pleumeekers HJ, Hoes AW, van der Does E, van Urk H, Hofman A, de Jong PT, et al. Aneurysms of th abdominal aorta in older adults. The Rotterdam Study. Am J Epidemiol. 1995; 142:1291-9.

11. Ishikawa S, Takahashi T, Sato Y, Suzuki M, Ohki S, Oshima K, et al. Screening cost for abdominal aortic aneurysms. Japan based estimates. Surg Today. 2004; 34:828-31.
12. Hoffman GS. Determinants of vessel targeting in vasculitis. Ann N Y Acad Sci. 2005;1051:332-9.

13. Ruddy JM, Jones JA, Spinale FG, Ikonomidis JS. Regional Heterogeneicity within the aorta. Relevance to aneurysm disease. J Thorac Cardiovasc Surg. 2008; 136:1123-30.

Access to The Journal of Thoracic and Cardiovascular Surgery Online is reserved for print subscribers!

Full-text access to The Journal of Thoracic and Cardiovascular Surgery Online is available for all print subscribers. To activate your individual online subscription, please visit The Journal of Thoracic and Cardiovascular Surgery Online, point your browser to http://www.mosby.com/jtcvs, follow the prompts to activate your online access, and follow the instructions. To activate your account, you will need your subscriber account number, which you can find on your mailing label (note: the number of digits in your subscriber account number varies from 6 to 10). See the example below in which the subscriber account number has been circled:

\section{Sample mailing label}

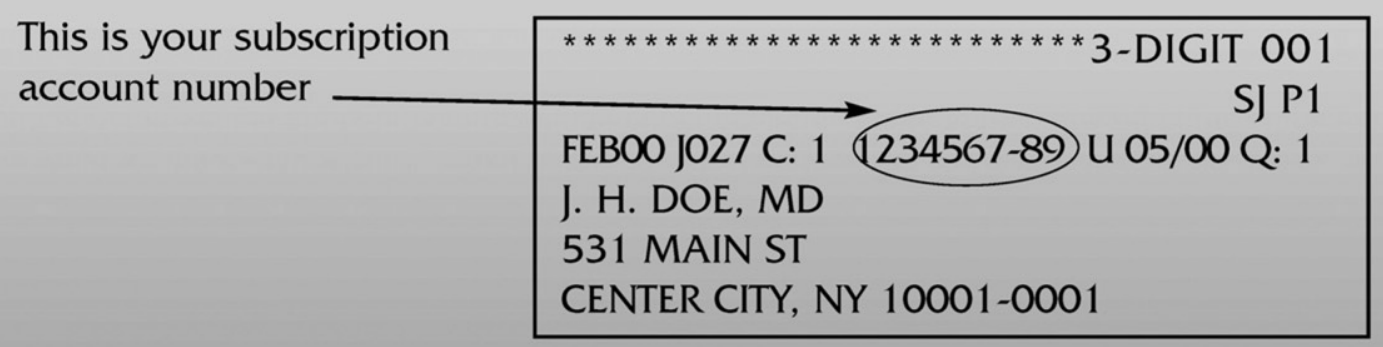

Personal subscriptions to The Journal of Thoracic and Cardiovascular Surgery Online are for individual use only and may not be transferred. Use of The Journal of Thoracic and Cardiovascular Surgery Online is subject to agreement to the terms and conditions as indicated online. 